\title{
MORFOLOGIA DE FRUTOS E SEMENTES E GERMINAÇÃO DE Poincianella pyramidalis (Tul.) L. P. Queiroz, comb. Nov
}

\author{
MORPHOLOGY OF FRUIT AND SEED AND GERMINATION ON \\ Poincianella pyramidalis (Tul.) L. P. Queiroz, comb. Nov
}

\author{
Andrea Vita Reis Mendonça ${ }^{1}$ Teresa Aparecida Soares de Freitas ${ }^{2}$ Leonardo Silva Souza ${ }^{3}$ \\ Mariana Duarte Silva Fonseca ${ }^{4}$ Josival Santos Souza ${ }^{5}$
}

\begin{abstract}
RESUMO
O objetivo deste trabalho foi descrever os caracteres morfológicos dos frutos, sementes e plântulas, caracterizar o processo de germinação e verificar se a posição da semente no fruto interfere na germinação de sementes de Poincianella pyramidalis. Os frutos foram coletados de cinco árvores-matrizes em propriedade rural situada no município de Castro Alves - BA - Brasil em área próxima a remanescentes de Caatinga sensu stricto e Floresta Estacional. O fruto de Poincianella pyramidalis é do tipo legume, polispérmico, deiscente, medindo, em média, 9,4 $\pm 0,08 \mathrm{~cm}$ de comprimento, podendo conter até 8 sementes por fruto, sendo o número médio de sementes, aparentemente viáveis, por 100 frutos de $280 \pm 29,8$. A semente é elipsoide de cor castanho-amarelada e superfície lisa, polida e dura, sendo provida de testa e tegma, com comprimento de $1,25 \pm 0,004 \mathrm{~cm}$. O embrião é axial, invaginado e reto e não foi verificada presença de endosperma. O peso de 1000 sementes foi de $106,8 \pm 12,4$ g. A germinação é epígea fanerocotiledonar, teve início no terceiro dia após a semeadura e a formação completa da plântula foi verificada no nono dia. A produção de sementes de Poincianella pyramidalis na posição proximal é inferior em relação às demais posições. O percentual de germinação é influenciado pela posição da semente no fruto, sementes na posição distal apresentam germinação inferior às sementes das demais posições.
\end{abstract}

Palavras-chave: Caesalpinia pyramidalis; catinga-de-porco; posição semente no fruto.

\begin{abstract}
The objective of this study was to describe the morphological characters of fruits, seeds and seedlings, characterize the germination process and verify that the seed position in the fruit interferes with the seed germination of Poincianella pyramidalis. The fruits were collected from five trees in the Castro Alves, Bahia - Brazil in the area near the remnants of Caatinga sensu stricto and Deciduous Forest. The fruit of Poincianella pyramidalis is a type of legume, polyspermic, dehiscent, measuring on average $9.4 \pm 0.08$ $\mathrm{cm}$ in length and can contain up to 8 seeds per fruit, being the average number of seeds, apparently viable fruits per $100 \pm 28029.8$. The seed is ellipsoid, yellowish brown color and smooth, polished and hard, being

1 Engenharia Florestal, Dr., Professor Adjunto do Centro de Ciências Agrárias Ambientais e Biológica, Universidade Federal do Recôncavo da Bahia, Rua Rui Barbosa, 710, Campus Universitário, CEP 44380-000, Cruz das Almas (BA), Brasil. andrea@ufrb.edu.br

2 Engenheira Agrônoma, Dr., Professor Adjunto do Centro de Ciências Agrárias Ambientais e Biológica, Universidade Federal do Recôncavo da Bahia, Rua Rui Barbosa, 710, Campus Universitário, CEP 44380-000, Cruz das Almas (BA) Brasil. teresa@ufrb.edu.br

3 Engenheiro Florestal, MSc., Doutorando em Ciências Agrárias no Centro de Ciências Agrárias Ambientais e Biológica, Universidade Federal do Recôncavo da Bahia, Rua Rui Barbosa, 710, Campus Universitário, CEP 44380-000, Cruz das Almas (BA), Brasil. leouenf@hotmail.com

4 Engenheira Florestal, Mestranda em Ciências Florestais, Universidade Federal do Espírito Santo, Av. Fernando Ferrari, 514, Goiabeiras, CEP 29075-910, Vitória (ES), Brasil. Duarte.123@hotmail.com

5 Engenheiro Florestal, Dr., Professor Adjunto do Centro de Ciências Agrárias Ambientais e Biológica, Universidade Federal do Recôncavo da Bahia, Rua Rui Barbosa, 710, Campus Universitário, CEP 44380-000, Cruz das Almas (BA) Brasil. josival@ufrb.edu.br
\end{abstract}

Recebido para publicação em 21/07/2011 e aceito em 29/08/2014 
provided testa and internal tegument, with a length of $1.25 \pm 0.004 \mathrm{~cm}$. The embryo is axis, invaginated and straight and there was no presence of endosperm. The weight of 1000 seeds was $106.8 \pm 12.4 \mathrm{~g}$. Germination is phanecotylar-epigious began the third day after sowing and the complete formation of the seedling was observed on the ninth day. Seed production of Poincianella pyramidalis in the proximal position is lower compared to other positions. Seed germination is influenced by seed position in the fruit, seeds present in the distal lower seed germination of other positions.

Keywords: Caesalpinia pyramidalis; catinga-de-porco; fruit position on seed.

\section{INTRODUÇÃO}

O reconhecimento de caracteres morfológicos de frutos e sementes, bem como dos estágios iniciais do desenvolvimento das plantas, constitui uma ferramenta para identificação de espécies (COSMO et al., 2009), contribui para o conhecimento do processo reprodutivo, fornece subsídio para produção de mudas e auxilia na compreensão do processo de regeneração natural (NUNES et al., 2009; GUERRA et al., 2006).

Além da caracterização morfológica de frutos, sementes e plântula, outra questão importante relativa à reprodução sexuada é se a posição da semente no fruto interfere no processo de germinação. Esta questão, embora discutida desde a década de 60, raramente é tema de trabalhos científicos. Entre os estudos que avaliam o efeito da posição da semente no fruto sobre a germinação, podem ser citados os trabalhos realizados por Freitas et al. (2013), Nogueira et al. (2010), Araújo et al. (2005), Mena-Ali e Rocha (2005), Silva et al. (1988) e Cardoso (1963).

A espécie Poincianella pyramidalis, popularmente conhecida como "catingueira" por ser típica de área de Caatinga, pertence à família Leguminosae e subfamília Caesalpinioideae, ocorre do Maranhão e Ceará até a Bahia, com uma disjunção no Amazonas (QUEIROZ, 2009). Santos et al. (2007) verificaram a ocorrência desta espécie em uma Floresta Estacional Decidual, no Parque Municipal da Sapucaia, Montes Claros - MG.

De acordo com Queiroz (2009), Poincianella pyramidalis apresenta boa capacidade de rebrota e crescimento rápido, sendo observada colonizando áreas recém-cortadas, indicando potencial para recuperação de áreas degradadas.

No projeto desenvolvido pela Associação Plantas do Nordeste, com o objetivo de identificar espécies da flora nordestina de importância econômica potencial, a Poincianella pyramidalis é indicada como potencial em duas categorias: potencial madeireiro e forrageiro (SAMPAIO et al., 2005). O potencial madeireiro se justifica porque a madeira desta espécie tem sido utilizada para estaca, mourões, construção de casas de taipa e como lenha e carvão (FIGUEIRÔA et al., 2005). A madeira de Poincianella pyramidalis, segundo Maia (2004), apresenta densidade de $0,99 \mathrm{~g} \mathrm{~cm}^{-3}$, alto teor de lignina e celulose, o que confirma seu potencial para produção de carvão. O potencial como forrageira é evidenciado pelo fato da espécie ter sido citada entre as dez com maior participação na dieta de bovinos, ovinos e caprinos em pastejo em área de caatinga em Serra Talhada - PE (BATISTA et al., 2005). Estudos têm também identificado Poincianella pyramidalis como espécie de potencial apícola (FREITAS; SILVA, 2006; MACHADO; LOPES, 2006).

Considerando a carência de estudos com sementes de espécies nativas, principalmente do semiárido brasileiro, e a importância ecológica e econômica de Poincianella pyramidalis, o objetivo deste trabalho foi descrever os caracteres morfológicos dos frutos, sementes e plântulas, caracterizar o processo de germinação e verificar se a posição da semente no fruto interfere na germinação de sementes desta espécie.

\section{MATERIAL E MÉTODO}

\section{Coleta dos frutos}

Os frutos de Poincianella pyramidalis foram coletados em propriedade rural particular, situada no município de Castro Alves - BA $\left(12^{\circ} 45^{\prime} 56^{\prime \prime} \mathrm{S}\right.$ e $39^{\circ} 25^{\prime} 42^{\prime \prime} \mathrm{W}$ ), altitude entre 262 a $278 \mathrm{~m}$, cujo clima da região é do tipo semiárido e subúmido a seco, precipitação anual varia entre 400 a 700 $\mathrm{mm}$ (SEI, 2000). Nesta propriedade encontram-se remanescentes de Caatinga sensu stricto e Floresta Estacional, segundo caracterização descrita por Queiroz (2009).

Para coleta dos frutos selecionaram-se cinco árvores-matrizes, distanciadas no mínimo 70 metros 
umas das outras, localizadas em área utilizada para pastagem de bovinos e próxima aos remanescentes de Caatinga sensu stricto e Floresta Estacional. Obtiveram-se as coordenadas de localização das matrizes (Tabela 1). A seleção das árvores-matrizes foi em função da disponibilidade de indivíduos da espécie em estudo na área.

A coleta dos frutos foi realizada entre setembro e outubro de 2010 , diretamente das árvores-matrizes, quando os mesmos se encontravam em fase intermediária de maturação, apresentando coloração marrom-esverdeada, segundo recomendação de Maia (2004). Os frutos coletados foram levados para o laboratório de sementes da Universidade Federal do Recôncavo da Bahia, Campus Cruz das Almas - BA, no qual, inicialmente, foram colocados para secar ao sol, por cinco dias, e posteriormente realizou-se abertura manual dos frutos para obtenção das sementes.

\section{Morfologia e biometria de frutos, sementes e plântulas}

Para morfologia do fruto foram considerados os seguintes aspectos: classificação do tipo, cor, dimensões (comprimento, largura e espessura), forma, textura e consistência do pericarpo, deiscência e número de sementes por fruto.

Para caracterização morfológica da semente observaram-se: cor, dimensões (comprimento, largura e espessura), forma, características do tegumento e do embrião e peso de 1000 sementes (13 subamostras de 100 sementes).

Para mensuração da biometria dos frutos foram utilizados 100 de cada árvore coletadas aleatoriamente, totalizando 500 e para a biometria das sementes mensurou-se aquelas resultantes dos 500 frutos mensurados.

O comprimento, a largura e a espessura dos frutos e sementes foram medidos, utilizando-se um paquímetro de precisão de $0,1 \mathrm{~mm}$, sendo o comprimento medido da base até o ápice e a espessura medida na linha mediana dos frutos e sementes. Para mensuração da largura foram realizadas medições na posição proximal, intermediaria e distal dos frutos e sementes. Foi adotada a terminologia para frutos e sementes de Barroso et al. (1999) e Gonçalvez e Lorenzi (2007). Os dados biométricos foram submetidos à análise estatística descritiva.

O acompanhamento do desenvolvimento das plântulas foi realizado em casa de vegetação. Foram semeadas diariamente seis sementes em bandeja de polietileno perfuradas e preenchidas com substrato comercial, até que as primeiras sementes atingissem o estádio de plântula, o qual foi considerado quando os eófilos se encontraram totalmente formados. Quando foi verificado que as plântulas semeadas no primeiro dia apresentaram o primeiro par de eófilos expandido, todas as sementes foram retiradas do substrato, obtendo-se assim todas as fases do desenvolvimento. Realizou-se neste momento a descrição da raiz (primária e secundária), coleto, hipocótilo, cotilédones, epicótilo e do primeiro par de eófilos.

A terminologia e a metodologia utilizadas para estudo morfológico basearam-se nos trabalhos de Barroso et al. (1999), Araújo et al. (2004), Vidal e Vidal (2006), Brasil (2009a) e Gonçalvez e Lorenzi (2007).

\section{Posição das sementes nos frutos}

Para a separação das sementes quanto à posição, empregou-se metodologia semelhante ao trabalho de Freitas et al. (2013), na qual o fruto foi subdividido em três regiões, a proximal, correspondente à região mais próxima ao pedúnculo, intermediária e distal. Quando o fruto apresentava número ímpar de falsos septos, separava-se a primeira semente proximal, a primeira distal e a posicionada na cavidade central

TABELA 1: Altura e coordenadas de localização das matrizes de Poincianella pyramidalis fornecedoras de sementes.

TABLE 1: Height and location coordinates of the matrices of Poincianella pyramidalis supplier for seeds.

\begin{tabular}{cccc}
\hline Matrizes & Altura da planta $(\mathrm{m})$ & Coordenada S & Coordenada W \\
\hline 1 & 7,5 & $12^{\circ} 44^{\prime} 51,9^{\prime \prime}$ & $39^{\circ} 26^{\prime} 40,9^{\prime \prime}$ \\
2 & 9,6 & $12^{\circ} 44^{\prime} 51,6^{\prime \prime}$ & $39^{\circ} 26^{\prime} 43,4^{\prime \prime}$ \\
3 & 11,2 & $12^{\circ} 44^{\prime} 45,2^{\prime \prime}$ & $39^{\circ} 26^{\prime} 57,5^{\prime}$ \\
4 & 6,7 & $12^{\circ} 44^{\prime} 59,9^{\prime \prime}$ & $39^{\circ} 26^{\prime} 52,5^{\prime \prime}$ \\
5 & 4,6 & $12^{\circ} 44^{\prime} 51,5^{\prime \prime}$ & $39^{\circ} 26^{\prime} 52,1^{\prime \prime}$ \\
\hline
\end{tabular}


e quando apresentava número par separava-se a primeira semente proximal, a primeira distal e as duas posicionadas nas cavidades centrais. Foram computadas também as sementes nas demais posições, sendo denominadas gerais.

Em cada 100 frutos de cada uma das cinco plantas foram computados o número de sementes de cada posição, bem como as dimensões (comprimento, largura e espessura) das mesmas e estes dados foram analisados pelo teste de quiquadrado $(\alpha=0,05)$.

Para avaliar se a posição do fruto interfere no percentual de germinação e índice de velocidade de germinação, foi montado um experimento em blocos casualizados, com cinco blocos (referentes às cinco matrizes que foram utilizadas para coleta de frutos). Os quatro tratamentos empregados foram sementes posicionadas na região proximal, intermediária, distal e demais posições (Geral). Cada repetição foi composta por 25 sementes. Os dados deste experimento foram submetidos à análise de variância $(\alpha=0,05)$, após a verificação dos pressupostos pelo teste de homocedasticidade (F máximo) e pelo teste de distribuição normal dos resíduos (Lilliefors).

O teste de germinação foi realizado em rolos de papel germitest umedecidos com água destilada na proporção de 2,5 vezes o peso do papel (BRASIL, 2009b). Os rolos de papel foram colocados dentro de sacos de polietileno, em seguida os rolos foram condicionados em câmara de germinação, tipo $\mathrm{BOD}$, a $30^{\circ} \mathrm{C}$, utilizando-se doze horas diárias de luz. Realizaram-se contagens no segundo e oitavo dia, sendo consideradas germinadas as sementes com protrusão da raiz primária. Determinando-se o percentual de germinação das plântulas normais e o índice de velocidade de germinação (MAGUIRE, 1962). No oitavo dia foram anotadas as plântulas anormais e sementes não germinadas. Foram consideradas plântulas anormais aquelas nas quais se observaram estruturas ausentes ou malformadas.

\section{RESULTADOS E DISCUSSÃO}

\section{Aspectos morfológicos e biometria de frutos, sementes e plântulas}

Fruto tipo legume, polispérmico, deiscente, pericarpo seco de textura lenhosa, superfície reticulada, pubescente e verde quando imaturo e marrom na maturidade. A superfície é, também, opaca, embora alguns poucos frutos apresentaramse glabros e de aspecto polido. A forma do fruto é oblanceolada, sendo mais largo próximo ao ápice em relação à base e a razão entre comprimento e largura central foi em média igual a quatro (Tabela 2), de acordo com definição de oblanceolada apresentada por Gonçalvez e Lorenzi (2007). O ápice do fruto termina abruptamente em ponta dura e aguda, denominada rostro (Figura 1A), cujo comprimento variou de 1,1 a 0,1 (Tabela 2), sendo, portanto, fruto apiculado (Figura 1A). Os dados biométricos do comprimento, largura e espessura dos frutos encontram-se na Tabela 2 , sendo que o comprimento do fruto variou de 5,41 a $14,36 \mathrm{~cm}$ e sua largura de 1,51 a 2,80 cm. De acordo com Queiroz (2009), a Poincianella pyramidalis apresenta frutos oblongooblanceolados com o comprimento variando entre 8 $-14 \mathrm{~cm}$ e largura variando de $1,8-3 \mathrm{~cm}$, o que está de acordo com o encontrado no presente trabalho.

$\mathrm{O}$ fruto abre-se elasticamente por torção leve na porção basal, sendo que as valvas não ficam

TABELA 2: Comprimento (C), Largura (L), Espessura (E) e Razão Comprimento/Largura (C/L) dos frutos de Poincianella pyramidalis.

TABLE 2: Length (C), Width (L), thickness (E) and length/width ratio $(\mathrm{C} / \mathrm{L})$ of the Poincianella pyramidalis fruits.

\begin{tabular}{|c|c|c|c|c|c|c|c|}
\hline \multirow{2}{*}{ Parâmetros } & \multicolumn{2}{|c|}{$\mathrm{C}(\mathrm{cm})$} & \multicolumn{3}{|c|}{$\mathrm{L}(\mathrm{cm})$} & \multirow{2}{*}{$\mathrm{E}(\mathrm{cm})$} & \multirow{2}{*}{$\mathrm{C} / \mathrm{L}$} \\
\hline & Total & Ponta & Distal & Central & Proximal & & \\
\hline Média & 9,38 & 0,44 & 2,20 & 2,22 & 1,73 & 0,38 & 4 \\
\hline Máximo & 14,36 & 1,10 & 2,79 & 2,80 & 2,40 & 0,79 & 6 \\
\hline Mínimo & 5,41 & 0,05 & 1,40 & 1,51 & 0,97 & 0,20 & 3 \\
\hline EPM & 0,076 & 0,009 & 0,010 & 0,010 & 0,013 & 0,004 & 0,03 \\
\hline $\mathrm{CV} \%$ & 18,1 & 43,4 & 10,2 & 10,3 & 16,7 & 20,8 & 13,4 \\
\hline
\end{tabular}

Em que: EPM = Erro Padrão da Média; CV\% = Coeficiente de Variação. 
totalmente espiraladas (Figura 1B). Queiroz (2009) também classificou o fruto da espécie em questão como com deiscência elástica.

De acordo com Barroso et al. (2004), a subfamília Caesalpinioideae, que apresentam frutos do tipo legume, pode abrir-se passivamente ou elasticamente, sendo que suas válvulas podem sofrer uma leve torção apenas na porção basal ou a torção é mais acentuada e atinge uma extensão maior.

Internamente, os frutos são providos de cavidades denominadas falsos septos nas quais ficam depositadas as sementes que se prendem ao fruto pelo funículo curto (Figura 1C). Silva e Môro (2008) analisando as estruturas de Clitoria fairchildiana também leguminosa observaram presença de falso septo.

O número de falsos septos variou de 4 a 9 e
96\% dos frutos apresentaram de 5 a 7 falsos septos (Figura 3A), sendo que em apenas $12 \%$ dos frutos todas as cavidades estavam providas de sementes.

O número de sementes por fruto variou de 0 a 8 e a maioria dos frutos apresentou 2,3 e 4 sementes (Figura 3B). O número médio de sementes aparentemente viáveis por 100 frutos, considerando os cinco indivíduos amostrados, foi de $280 \pm 29,8$. De acordo com Barroso et al. (2004), nos gêneros das Caesalpinias, o número de sementes pode variar, podendo ser encontrado desde frutos monospermos (uma semente por fruto) como frutos polispermos (mais de uma semente por fruto).

Barroso et al. (2004) ressaltam que o legume é o tipo de fruto típico de espécies da família Fabaceae (Leguminosae), ocorrendo uma intensa diversidade morfológica principalmente nas formas de deiscências, na ausência ou presença de septos,

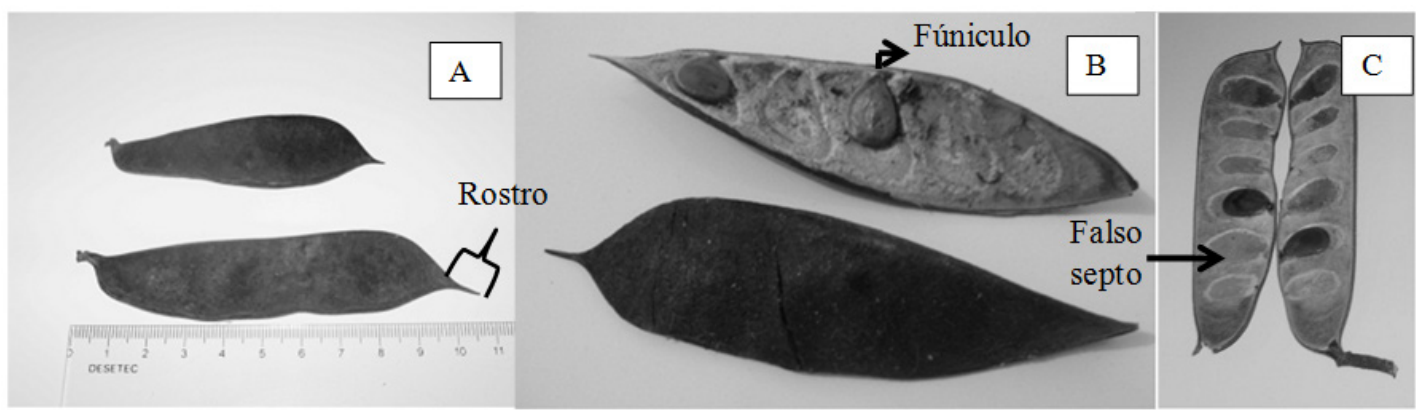

FIGURA 1: A- Fruto de Poincianella pyramidalis antes da abertura; B- Fruto de Poincianella pyramidalis após deiscência elástica e $\mathbf{C}$ - Semente de Poincianella pyramidalis aderidas aos frutos.

FIGURE 1: A- Fruit of Poincianella pyramidalis before of opening; B- Fruit of Poincianella pyramidalis after elastic dehiscence and $\mathbf{C}$ - Poincianella pyramidalis seed attached to the fruits.
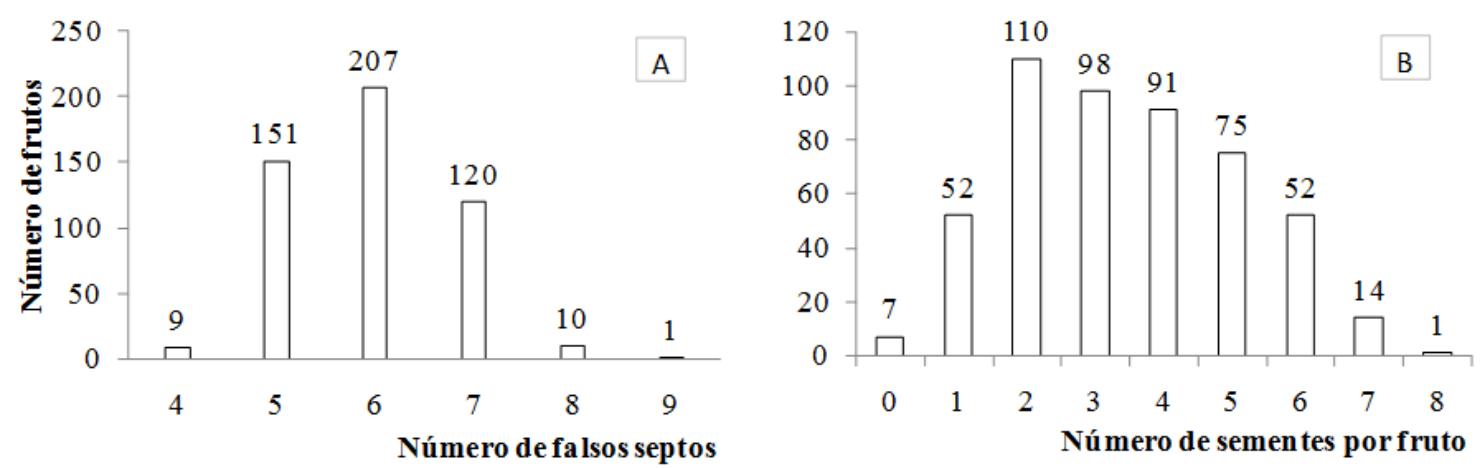

FIGURA 3: A- Distribuição de frequência de frutos por número de falsos septos por fruto de Poincianella pyramidalis; B- Distribuição de frequência de frutos por número de sementes por fruto de Poincianella pyramidalis.

FIGURE 3: A- Frequency distribution of fruit for number of false septa for Poincianella pyramidalis fruit; B -Frequency distribution of the fruit for number of seeds for Poincianella pyramidalis fruit. 
como também no número de sementes.

A semente apresenta forma elipsoide, cor castanho-amarelada e superfície lisa, polida e dura (Figura 4A). É provida de testa e tegma, embora Barroso et al. (1999) afirmem que, normalmente, a subfamília Caesalpinioideae possui apenas testa, sendo o tegma reabsorvido. Quando imersa em água, por pelo menos seis horas, é possível observar a testa caracterizada por uma película muito fina e membranácea aderida ao tegma. $\mathrm{O}$ tegma apresenta cor marrom e consistência também membranácea, porém, de maior espessura em relação à testa. A Figura 4B mostra a semente após seis horas de imersão em água, sendo possível observar a testa fina se desprendendo do tegma.

O hilo é terminal (apical), diminuto e elíptico e a calaza se caracteriza por uma mancha em tonalidade mais clara margeando a região do hilo (Figuras 5 A e B). O embrião ocupa o eixo central da semente, sendo axial, invaginado e reto, de tamanho pequeno, menor do que um terço do comprimento da semente (Figuras $5 \mathrm{C}$ e D). Os cotilédones são amarelos elípticos e não diferem da cor do embrião. Não foi verificada presença de endosperma.

Silva et al. (2014) estudando uma espécie da família das leguminosas da Caatinga, também não observaram a presença do endosperma. De acordo com Gunn (1981), citado por Amorim et al. (2008),

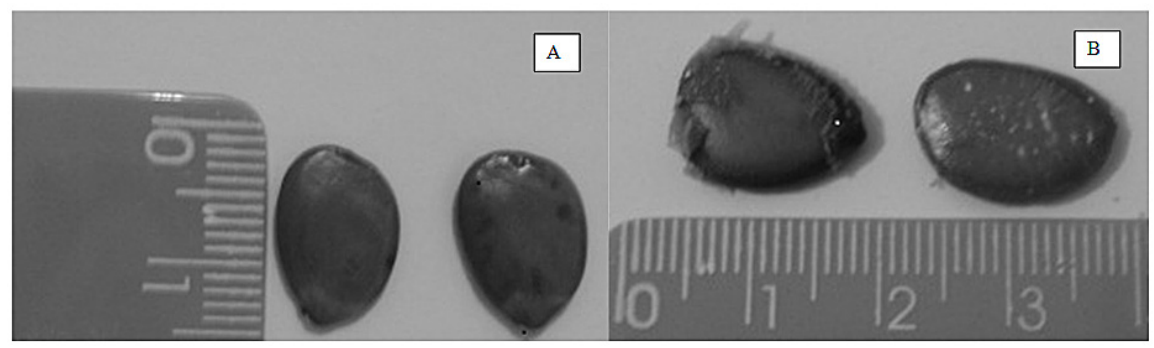

FIGURA 4: Semente de Poincianella pyramidalis antes (A) e após imersão em água (B). FIGURE 4: Poincianella pyramidalis seed before (A) and after immension in water (B).

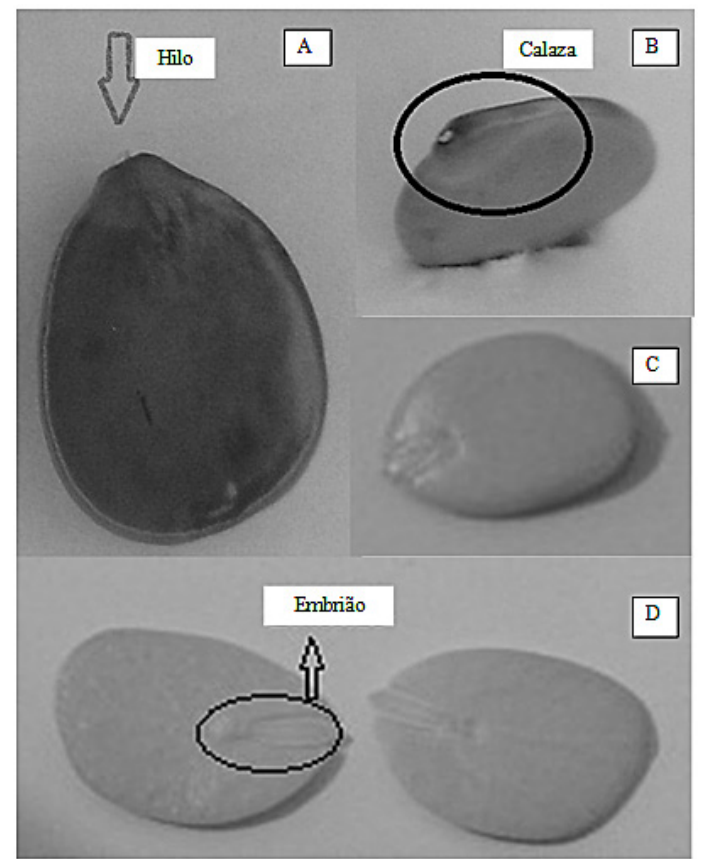

FIGURA 5: Sementes de Poincianella pyramidalis: A - Hilo; B - Calaza; C - Semente sem tegumento com cotilédones unidos; D - Semente sem tegumento com cotilédones abertos, visualizando embrião.

FIGURE 5: Poincianella pyramidalis seeds: A - Hilum; B - chalaza; C - Seed without tegument with cotyledons together; D - Seed without tegument with open cotyledons visualizing embryo. 
que estudou 5 tribos, com 110 gêneros e 1900 espécies desta subfamília, o endosperma estava presente em apenas $32 \%$ dos gêneros.

As dimensões médias de comprimento, largura na posição intermediária e espessura das sementes foram respectivamente: $1,25 \pm 0,004 \mathrm{~cm}, 0,81 \pm$ 0,003 e $0,16 \pm 0,002$ (Tabela 3 ).

O peso de 1000 sementes de Poincianella pyramidalis foi de $106,8 \mathrm{~g} \pm 12,4 \mathrm{~g}$, com coeficiente de variação de $43,4 \%$.

Estudos morfológicos de sementes são úteis na identificação de espécies encontradas em bancos de sementes. De acordo com Silva et al. (2008), através das sementes com suas características básicas podem ser identificadas famílias, gênero, espécie ou até mesmo variedade de uma planta.

A germinação epígea fanerocotiledonar teve início no terceiro dia após a semeadura, com o rompimento do tegumento e surgimento da radícula na parte basal da semente, próximo ao hilo, apresentando-se tenra, cilíndrica e de coloração esbranquiçada, tornando-se, com o desenvolvimento, afinada da base para o ápice e adquirindo coloração amarronzada da base do coleto ao ápice; coleto evidente pela dilatação na região e de coloração marrom; coifa não evidente (Figura 6).

A germinação fanerocotiledonar também foi descrita por Amorim et al. (2008) para Senna multijuga; por Battilani et al. (2011) para Guibourtia hymenifolia; por Nogueira et al. (2010)

TABELA 3: Comprimento (C), Largura (Proximal (P) Intermediária (I) e Distal (D)) e espessura (E) em centímetros das sementes de Poincianella pyramidalis.

TABLE 3: Length (L), width (Proximal (P) Intermediary (I) and Distal (D)) and thickness (E) in centimeters of the Poincianella pyramidalis seed.

\begin{tabular}{|c|c|c|c|c|c|}
\hline \multirow{2}{*}{ Parâmetros } & \multicolumn{4}{|c|}{ Largura $(\mathrm{cm})$} & \multirow{2}{*}{$\mathrm{E}(\mathrm{cm})$} \\
\hline & $\mathrm{C}(\mathrm{cm})$ & $\mathrm{P}$ & I & $\mathrm{D}$ & \\
\hline Média & 1,25 & 0,69 & 0,81 & 0,71 & 0,16 \\
\hline Máximo & 1,89 & 1,20 & 1,23 & 1,12 & 1,15 \\
\hline Mínimo & 0,58 & 0,18 & 0,04 & 0,10 & 0,01 \\
\hline EPM & 0,004 & 0,003 & 0,003 & 0,003 & 0,002 \\
\hline$\% \mathrm{CV}$ & 13,1 & 18,6 & 15,3 & 16,4 & 45,5 \\
\hline
\end{tabular}

Em que: EPM = Erro Padrão da Média; CV\% = Coeficiente de Variação.

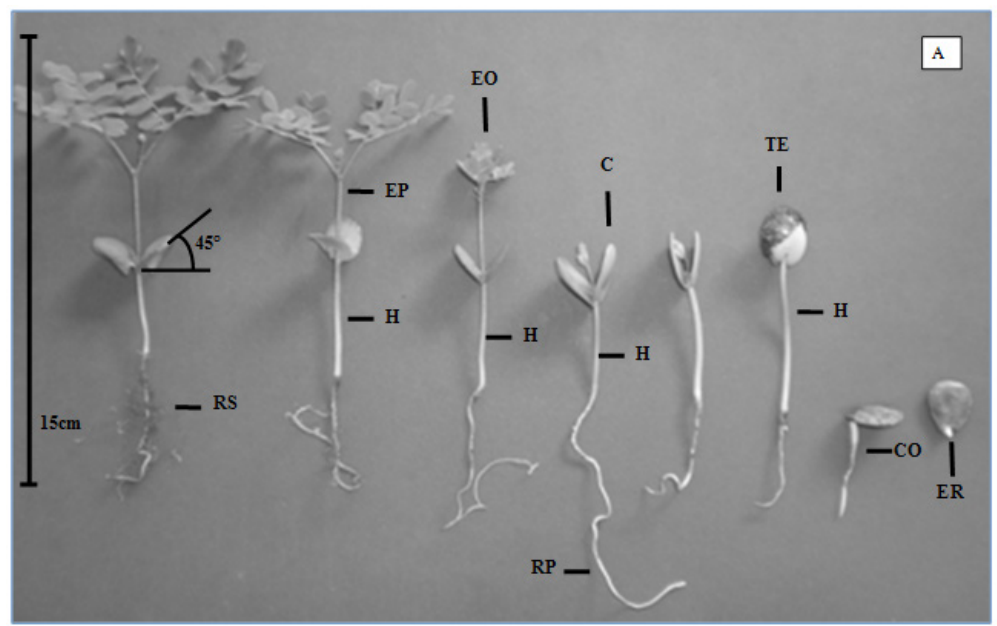

FIGURA 6: Fases do desenvolvimento pós-seminal de Poincianella pyramidalis. Em que: RS - raiz secundária; EO - eófilo; RP - raiz primária; C - cotilédones; H - hipocótilo; ER - emissão da radícula; CO- Coleto; TE - Tegumento.

FIGURE 6: Stages of development post-seminal Poincianella pyramidalis. Where: RS - Secundary root; EO - first pair of leaves; RP - Primary root; C - Cotyledons; H - Hypocotyl; ER - Radicle protrusion; CO- Coleto; TE - Tegument. 


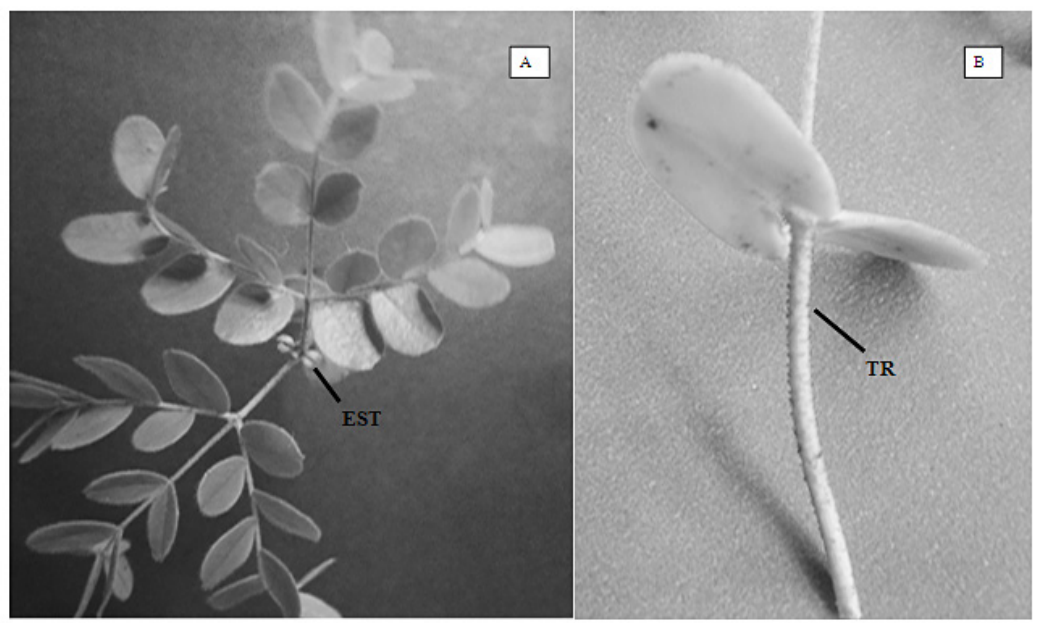

FIGURA 7: (A) Detalhe da estípula. Em que: EST - estípula. (B) Detalhe dos tricomas. Em que: TR tricoma.

FIGURE 7: (A) Detail of Stipule. Where: EST - Stipule. (B) Detail of trichomes. Where: TR - Trichomes.

para Dalbergia cearensis; e por Oliveira (2001) para Erythrina speciosa, sendo todas as espécies pertencentes à família das Leguminosae (Fabaceae).

A emersão da plântula do substrato ocorreu ao sexto dia, com o tegumento ainda aderido aos cotilédones. O hipocótilo é inicialmente curvo tornando-se ereto, cilíndrico, tenro, com comprimento entre 17,3 e $26,50 \mathrm{~mm}$, de coloração esverdeada, com tricomas curtos e finos de maior concentração abaixo do cotilédone que vão se dispersando até a base do hipocótilo (Figura 7B); apresenta uma estria amarronzada evidente desde o coleto até um pouco acima do hipocótilo. Nesta fase, a raiz primaria inicia a lignificação medindose entre 32,80 e $68,90 \mathrm{~mm}$. Os cotilédones se apresentam opostos, isófilos, de consistência carnácea, superfície glabra, coloração verde, com pontos escuros ao redor da borda e com nervura evidente na parte abaxial (Figura 6).

No oitavo dia observou-se a formação dos primórdios de raízes secundárias um pouco abaixo do coleto, com coloração esbranquiçada, que se tornam finas e alongadas; e a emissão do epicótilo com o primeiro par de eófilos recompostos, com par de estipulas opostas e oblanceoladas (Figura 7A) e pecíolo com tricomas esparsos de coloração marrom.

As estipulas também foram observadas em outras espécies da família de Leguminosae (Fabaceae) como Senna multijuga (AMORIM et al., 2008), Guibourtia hymenifolia (BATTILANI et al., 2011) e Erythrina speciosa, Holocalyx balansae, Swartzia langsdorffii e Platycyamus regnellii
(OLIVEIRA, 2001) e de acordo com Battilani et al. (2011), a presença das estípulas pode ser considerada relevante em estudos taxonômicos e filogenéticos para espécies de leguminosas.

A partir do nono dia, tem-se a plântula normal (Figura 6). Apresenta sistema radicular pivotante com comprimento variando de 28,60 a $44,80 \mathrm{~mm}$. O hipocótilo é cilíndrico, esverdeado, medindo de 27,80 a $46,50 \mathrm{~mm}$ de comprimento, com tricomas de coloração marrom-clara (Figura 7B). O epicótilo é verde medindo de 26,20 a 46,50 $\mathrm{mm}$, lenticelado, cilíndrico e recoberto por tricomas. Os eófilos são perciolados, opostos, recompostos, tripenados, paripenados, com tricomas esparsos e apresentando na sua base um par de estípulas opostas entre eles. Folíolos perciolados, tendo a rafe com tricomas. Folíolos alternos, membranáceos, séssil, de base assimétrica, bordos inteiros, ápice subagudo, coloração verde-escura na face adaxial e verde-clara com tricomas na face abaxial, com venação foliar cladódroma, evidente também na face abaxial dos foliólulos. Os cotilédones apresentaram-se verdes, carnosos, com base sagitada, ápice obtuso, borda ondulado, superfície glabra com pontos pretos na face adaxial, e distando do eixo do epicótilo a uma angulação de aproximadamente $45^{\circ}$ (Figura 6).

De acordo com Queiroz (2009), a taxonomia das espécies de Caatinga não é uma tarefa simples, uma vez que muitas espécies apresentam superposição em alguns caracteres diagnósticos, o que torna o estudo da morfologia de frutos, sementes e plântula de grande importância para auxiliar na identificação e diferenciação das espécies existentes na Caatinga 
do gênero de Poincianella.

\section{Posição da semente no fruto}

Realizou-se Teste de qui-quadrado $\left(\mathrm{c}^{2}\right)$ aderência comparando a frequência esperada, caso não houvesse predominância da proporção de distal em relação a proximal (proporção de 1:2:1 para proximal, intermediária e distal, respectivamente) com a frequência observada. Verificou-se que, conforme o observado, os frutos apresentaram maior proporção de sementes do que o esperado na posição distal e menor para proximal, o que indica que, nesta espécie, a produção de sementes na posição distal é superior em relação à proximal (Tabela 4). MenaAli e Rocha (2005), estudando o efeito da posição sobre fertilização do óvulo e maturação da semente, observaram que os óvulos posicionados na região terminal do ovário (mais próxima ao pedúnculo) mostraram menor probabilidade de fertilização e maturação da semente.

Sabe-se que a maioria das flores produz mais óvulos do que o número de sementes maduras, isto porque as flores não recebem pólen suficiente para fertilização de todos os óvulos ou os óvulos eventualmente abortam (JOHNSON; NILSON, 1999). Segundo Mena-Ali e Rocha (2005), normalmente, as flores recebem quantidade suficiente de pólen para fertilização completa de seus óvulos, mas há alta incidência de aborto na maioria das espécies. Existem várias hipóteses propostas para explicar a elevada incidência de aborto em muitas espécies de plantas, tais como: expressão letal ou deletéria de alelos, devido, por exemplo, à homozigose resultante da perda de variabilidade genética das populações; competição por recursos o que favoreceria o zigoto mais próximo á fonte de recursos (LEE; BAZZAZ, 1982), explicação que contraria os resultados apresentados na Tabela 5, nos quais as posições mais próximas ao pedúnculo apresentaram maior incidência de aborto; a outra explicação é a competição do gametófito para acessar o óvulo, os óvulos localizados mais próximos à entrada do pólen (região distal) apresentam uma menor probabilidade de aborto em comparação aos localizados mais distantes (MOHAN RAJU et al., 1996). Esta última hipótese corrobora os resultados encontrados neste estudo, os quais evidenciam o favorecimento da posição distal em relação a proximal em número de sementes aparentemente bem formadas.

As distribuições de frequência do número de sementes por classes de comprimento (Tabela 5), espessura (Tabela 6) e largura mediana da semente

TABELA 4: Teste de qui-quadrado para proporção de sementes por posição no fruto de Poincianella pyramidalis.

TABLE 4: Chi-Quadrate test for proportion of seeds for fruit position the Poincianella pyramidalis.

\begin{tabular}{ccc}
\hline Posição & Frequência observada & Frequência esperada \\
\hline Proximal & 149 & 197,75 \\
Intermediária & 346 & 395,50 \\
Distal & 296 & 197,75 \\
\hline
\end{tabular}

Em que: $\mathrm{c}^{2}$ calculado $=67,03 ; \mathrm{c}^{2}$ tabelado $(\alpha=0,05)=5,99$

TABELA 5: Número de sementes por classe de comprimento de semente nas diferentes posições do fruto de Poincianella pyramidalis.

TABLE 5: Number of seeds for length class of seed in different positions of the fruit the Poincianella pyramidalis.

\begin{tabular}{ccccc}
\hline \multicolumn{5}{c}{ Classes $(\mathrm{cm})$} \\
\hline Posição & $<1,02$ & 1,02 a 1,24 & 1,24 a 1,45 & $>1,45$ \\
Distal & $42(30,7)$ & $63(90,8)$ & $163(151,3)$ & $28(23,3)$ \\
Geral & $44(63)$ & $178(186,4)$ & $326(310,7)$ & $60(47,8)$ \\
Intermediária & $24(35,9)$ & $102(106,1)$ & $199(176,8)$ & $21(27,2)$ \\
Proximal & $35(15,4)$ & $86(45,7)$ & $27(76,2)$ & $1(11,7)$ \\
\hline
\end{tabular}

Em que: $c^{2}$ calculado $=134,65 \quad c^{2}$ tabelado $=26,3 \quad$ Valores esperados entre parênteses () 
(Tabela 7) não são homogêneas entre as posições das sementes nos frutos, conforme indica o teste de qui-quadrado.

As sementes da posição proximal estão predominantemente nas menores classes de comprimento (Tabela 5) e com relação à espessura se observa menor número de sementes na maior classe do que o esperado para a referida posição (Tabela 6).
Embora a Poincianella pyramidalis apresente maior número de sementes por fruto na posição distal em relação à proximal e que na posição proximal predominam sementes de menor comprimento, constatou-se que o percentual médio de germinação das sementes da posição distal é inferior aos das demais posições, enquanto a posição da semente no fruto não influenciou o índice de velocidade de germinação (Tabela 8).

TABELA 6: Número de sementes por classe de espessura de semente nas diferentes posições do fruto de Poincianella pyramidalis.

TABLE 6: Number of seeds for seed depth class in different position of the fruit the Poincianella pyramidalis.

\begin{tabular}{lccccc}
\hline \multicolumn{5}{c}{ Classes $(\mathrm{cm})$} \\
\hline Posição & $<0,09$ & 0,09 a 0,13 & 0,13 a 0,17 & 0,17 a 0,21 & $>0,21$ \\
Distal & $46(31,7)$ & $65(68,6)$ & $45(51,7)$ & $96(103,3)$ & $44(40,7)$ \\
Geral & $44(64,2)$ & $150(138,8)$ & $109(104,7)$ & $211(209)$ & $85(82,3)$ \\
Intermediária & $36(37,1)$ & $76(80,2)$ & $56(60,5)$ & $123(120,7)$ & $55(47,5)$ \\
Proximal & $23(16)$ & $31(34,5)$ & $33(26)$ & $55(52)$ & $7(20,5)$ \\
\hline
\end{tabular}

Em que: $\mathrm{c}^{2}$ calculado $=31,96 ; \mathrm{c}^{2}$ tabelado $=26,3 ;(\mathrm{)})$ valores esperados entre parênteses.

TABELA 7: Número de sementes por classe de largura de semente nas diferentes posições do fruto de Poincianella pyramidalis.

TABLE 7: Number of seeds for seed class width in different position of the fruit the Poincianella pyramidalis.

\begin{tabular}{lcccc}
\hline \multicolumn{5}{c}{ Classes $(\mathrm{cm})$} \\
\hline Posição & $<0,53$ & 0,53 a 0,71 & 0,71 a 0,88 & $>0,88$ \\
Distal & $4(5,9)$ & $70(52,7)$ & $151(144,7)$ & $71(92,7)$ \\
Geral & $10(12,2)$ & $94(108,2)$ & $299(297,3)$ & $205(190,4)$ \\
Intermediária & $10(6,9)$ & $57(61,6)$ & $160(169,2)$ & $119(108,3)$ \\
\hline Proximal & $4(3)$ & $28(26,5)$ & $74(72,8)$ & $43(46,6)$ \\
\hline
\end{tabular}

Em que: $\mathrm{c}^{2}$ calculado $=19,04 \quad \mathrm{c}^{2}$ tabelado $=16,92 \quad$ Valores esperados entre parênteses ()

TABELA 8: Média de percentagem Germinação (\%G) e Índice de Velocidade de Germinação (IVG) por posição de sementes no fruto de Poincianella pyramidalis.

TABLE 8: Average percentage of germination $(\% \mathrm{G})$ and Germination Speed Index (IVG) seed position in the fruit of Poincianella pyramidalis.

\begin{tabular}{lcc}
\hline \multicolumn{1}{r}{ Posição } & $\% \mathrm{G}$ & IVG \\
\hline Geral & $66,4 \mathrm{a}$ & $4,45 \mathrm{a}$ \\
Intermediária & $62,4 \mathrm{ab}$ & $4,70 \mathrm{a}$ \\
Proximal & $59,2 \mathrm{ab}$ & $5,03 \mathrm{a}$ \\
Distal & $47,2 \mathrm{c}$ & $4,38 \mathrm{a}$ \\
\hline \multicolumn{1}{c}{ (DMS 5\%) } & $5,73(\mathrm{CV} \%=12,23)$ & $0,93(\mathrm{CV} \%=23,19)$
\end{tabular}

Em que: DMS = Diferença mínima significativa; $\mathrm{CV} \%=$ Coeficiente de variação. 
A menor percentagem de germinação na posição distal pode ser devido à desvantagem de sementes localizadas nesta posição com relação à competição por recursos. Segundo Bawa e Buckley (1989), a semente localizada mais próxima ao pedúnculo do fruto (fonte de recurso nutricional) será favorecida nutricionalmente em comparação às outras sementes, sendo esta competição mais intensa em frutos alongados, como as vagens das leguminosas, na qual a disposição linear das sementes pode diminuir o fluxo de recursos nutricionais de uma semente para outra. Assim, a competição por recursos, conforme colocado por Lee e Bazzaz (1982), pode favorecer o zigoto mais próximo, mas não diminui a probabilidade de aborto.

Estes resultados levam a uma reflexão importante do ponto de vista prático, a posição da semente no fruto interfere no desempenho germinativo na espécie em questão, assim no caso de comercialização de sementes desta espécie é recomendado separar estas sementes por posição, tendo maior valor aquelas provenientes de posições beneficiadas quanto à germinação. Como são quase inexistentes os estudos sobre influência da posição da semente no fruto sobre a germinação para as diferentes espécies vegetais, tanto florestais quando agrícolas, torna-se necessário ampliar estes estudos para maior segurança do mercado de sementes.

Os resultados levam também a supor que as sementes maiores não são favorecidas no processo de germinação, entretanto, com os dados coletados neste estudo, não é possível inferir seguramente sobre esta questão. Futuros estudos avaliando conjuntamente o efeito da posição da semente no fruto e o seu tamanho na germinação devem ser realizados para confirmar tal suposição.

\section{CONCLUSÕES}

Com base nos resultados obtidos nesse trabalho, a formação completa da plântula de Poincianella pyramidalis se dá no nono dia.

A produção de sementes de Poincianella pyramidalis na posição proximal é inferior em relação às demais posições.

O percentual de germinação de Poincianella pyramidalis é influenciado pela posição da semente no fruto e sementes na posição distal apresentam germinação inferior às sementes das demais posições.

\section{AGRADECIMENTOS}

Agradecemos a Eduardo José Nascimento e Maria do Carmo de Andrade Nascimento, proprietários da fazenda onde foram coletados os frutos, por permitirem o acesso ao local e apoio logístico (alojamento, alimentação, entre outros), auxiliando no desenvolvimento de importantes pesquisas na área florestal.

\section{REFERÊNCIAS BIBLIOGRÁFICAS}

AMORIM, I. L. de et al. Morfologia de frutos, sementes, plântulas e mudas de Senna multijuga var. lindleyana (Gardner) H. S. Irwin \& Barneby Leguminosae Caesalpinioideae. Revista Brasileira

Botânica, São Paulo, v. 31, n. 3, p. 507-516. 2008. ARAÚJO, E. C. de et al. Caracterização morfológica de frutos, sementes e plântulas de Sesbania virgata (cav.) Pers. Revista Brasileira de Sementes, Londrina, v. 26, n. 1, p. 105-110, 2004.

Efeito do armazenamento na qualidade fisiológica de sementes de mamão (Carica papaya 1.) em função da posição no fruto. In: SIMPÓSIO DO PAPAYA BRASILEIRO, 2005, Vitória. Anais... Vitória: ENCAPER, 2005, p. 270-272. Disponível em: <http://www.incaper.es.gov.br/pi-mamao/ index.php?a=papaya_2005/apresentacao $>$. Acesso em: 20 Jun. 2011

BARRoso, G. M. et al. Frutos e sementes. Morfologia aplicada à sistemática de dicotiledôneas. Viçosa: UFV, 1999. 443 p.

Frutos e sementes. Morfologia aplicada à sistemática de dicotiledôneas. Viçosa: UFV, 2004. $443 \mathrm{p}$.

BATISTA, A. M. V. et al. Forrageiras. In: SAMPAIO, E. V. S. B. et al. Espécies da flora nordestina de importância econômica potencial. Recife: Associação de Plantas do Nordeste, 2005. p. 27-48. BATTILANI, J. L. et al. Morfologia de frutos, sementes, plântulas e plantas jovens de Guibourtia hymenifolia (Moric.) J. Leonard (Fabaceae). Revista Árvore, Viçosa, v. 35, n. 5, p. 1089-1098, 2011.

BAWA, K. S.; D. P. BUCKLEY. Seed: ovules ratios, selective seed abortion and mating systems in Leguminosae. In: Monographs in Systematic Botany from the Missouri Botanical Garden, v. 29, p. 243-262, 1989.

BRASIL. Ministério da Agricultura, Pecuária e Abastecimento - Secretaria de Defesa Agropecuária. Glossário ilustrado de morfologia. Mapa/ACS, 
Brasília, Brasil. 2009a. 406 p. (ordem alfabética - é necessário trocar a e b, aqui e no texto - Glossário antes de Regras - mesmo autor)

Ministério da Agricultura, Pecuária e Abastecimento - Secretaria de Defesa Agropecuária. Regras para Análise de Sementes. Brasília: Mapa/ACS, 2009b. 399 p.

CARDOSO, M. Influência da posição das sementes no fruto do cacaueiro sobre a germinação e desenvolvimento das mudas. Bracatinga, Campinas, v. 22, n. 36, p. 461-464, 1963.

COSMO, N. L. et al. Morfologia do fruto, da semente e morfo-anatomia da plântula de Vitex megapotamica (Spreng.) Moldenke (Lamiaceae). Acta Botanica Brasilica, Belo Horizonte, v. 23, n. 2, p. 389-397, 2009.

FIGUEIRÔA, J. M. et al. Madeireiras. In: SAMPAIO, E. V. S. B. et al. Espécies da flora nordestina de importância econômica potencial. Recife: Associação de Plantas do Nordeste, 2005. p. 101-133.

FREITAS, B. M.; SILVA, E. M. S. Potencial apícula da vegetação do semi-árido brasileiro. In: SANTOS, F. A. R. Apium plantae. Instituto do Milênio do Semi-árido. Recife: IMSEAR, 2006, v. 3, p. 19-32. FREITAS, T. P. et al. Morfologia e caracterização da germinação em função da posição das sementes no fruto de sabiá. Scientia Plena, Sergipe, v. 9, n. 3, p. 1-9, 2013.

GUERRA, M. E. C. et al. Morfologia de sementes, de plântulas e da germinação de Copaifera langsdorfii Desf. (Leguminosae - Caesalpinioideae). Cerne, Lavras, v. 12, p. 322-328, 2006.

GONÇALVEZ, E. G.; LORENZI, L. Morfologia vegetal: organografia e dicionário ilustrado de morfologia de plantas vasculares. Instituto Plantarum de Estudos da Flora, 2007. 416 p.

JOHNSON S. D.; NILSSON L. A. Pollen carryover, geitonogamy, and the evolution of deceptive pollination systems in orchids. Ecology, v. 80, p. 2607-2619, 1999.

LEE T. D.; BAZZAZ, F. A. Regulation of fruit and seed production in an annual legume, Cassia fasciculata. Ecology, v. 63, p. 1363-1373, 1982.

MACHADO, I. C.; LOPES, A. V. Melitofilia em espécies de caatinga em Pernambuco e estudos relacionados existentes no ecossistema. In: SANTOS, F. A. R. Apium plantae. Instituto do Milênio do Semi-árido, Recife: IMSEAR, v. 3, 2006. p. 33-60.

MAGUIRE, J. D. Speed of germination aid in selection and evaluation for seedling emergence and vigor. Crop Science, v. 2, n. 1, p. 176-177, 1962. MAIA, G. N. Caatinga: árvores e arbustos e suas utilidades. São Paulo, 2004. 413 p.

MENA-ALI, J. I.; ROCHA, O. J. Effect of Ovule Position within the Pod on the Probability of Seed Production in Bauhinia ungulata (Fabaceae). Annals of Botany, v. 95, p. 449-455, 2005.

MOHAN RAJU, B. et al. Intra-fruit seed abortion in a wind dispersed tree, Dalbergia sissoo Roxb: proximate mechanisms. Sexual Plant Reproduction, v. 9, p. 273-278, 1996.

NOGUEIRA, F. C. B. et al. Caracterização da germinação e morfologia de frutos, sementes e plântulas de Dalbergia cearensis Ducke (pau-violeta) - Fabaceae. Acta Botânica Brasilica, Belo Horizonte. v. 24, n. 4, p. 978-985, 2010.

NUNES, C. F. et al. Morfologia externa de frutos, sementes e plântulas de pinhão-manso. Pesquisa Agropecuária Brasileira, Brasília, v. 44, n. 2, p. 207-210, 2009.

OLIVEIRA, D. M. T. Morfologia comparada de plântulas e plantas jovens de leguminosas arbóreas nativas: espécies de Phaseoleae, Sophoreae, Swartzieae e Tephrosieae. Revista Brasileira Botânica. São Paulo, v. 24, n. 1, p. 85-97, 2001.

QUEIROZ, L. P. Leguminosas da Caatinga. Feira de Santana-BA: Universidade Estadual de Feira de Santana, 2009. 467 p.

SAMPAIO, E. V. S. B. et al. Espécies da flora nordestina de importância econômica potencial. Recife: Associação de Plantas do Nordeste, 2005. $331 \mathrm{p}$.

SANTOS, R. M. et al. Florística e estrutura de uma floresta estacional decidual, no Parque Municipal da Sapucaia, Montes Claros (MG). Cerne, Lavras, v. 13, n. 3, p. 248-256, 2007.

SEI. Superintendência de estudos econômicos e sociais da Bahia. Base Cartográfica: Divisão política administrativa-Estado da Bahia (Mapa), escala 1:1.500.000. 2000. Disponível em: < http:// www.sei.ba.gov.br/>. Acesso em: 11 dez. 2012.

SILVA, A. A. et al. Germinação e vigor de sementes de Crotalaria ianceolata E. Mey. 1. Influência da cor do tegumento e da posição dos frutos na infrutescência. Revista Brasileira de Sementes, Londrina v. 10, n. 2, p. 67-73, 1988.

SILVA, B. M. S. E.; MÔRO, F. V. Aspectos morfológicosdo fruto, da semente e desenvolvimento pós-seminal de faveira (Clitoria fairchildiana R. A. Howard. - FABACEAE. Revista Brasileira de Sementes, Londrina, v. 30, n. 3, p. 195-201, 2008. SILVA, K. B. et al. Morfologia de frutos, sementes, 
plântulas e plantas de Erythrina velutina willd., Leguminoseae - Papilionideae. Revista Brasileira de Sementes, v. 30, n. 3, p. 104-114, 2008.

Morfometria de frutos e diásporos de Acacia farnesiana (L.) Willd. Revista Verde de
Agroecologia e Desenvolvimento Sustentável, v. 9 , n. 2 , p. $76-82,2014$.

VIDAL, W. N., VIDAL, M. R. R. Botânica organografia: quadros sinóticos ilustrados de fanerógamos. UFV, Viçosa, 2006. 124 p. 